4. Zellenzahl der Drüsenhaare auf den großen Nerven $\quad \mathrm{L}<\mathrm{H}>\mathrm{J}$

5. Dicke der Drüsenhaare am Blattrand

$\mathrm{L} \div \mathrm{H} \div \mathrm{J}$

6. Dicke der Deckhaare am Blattrand

$\mathrm{L}>\mathrm{H}>\mathrm{J}$

7. Zahlenverhältnis zwischen Drüsenhaaren und Deckhaaren am Blattrande

$\mathrm{L}=\mathbf{H}>\mathrm{J}$

8. Spaltöffnungszahl auf der Blattoberseite

$\mathrm{L}>\mathrm{H}>\mathrm{J}$

9. Größe der Spaltöffnungen

$\mathrm{L}>\mathrm{H}>\mathrm{J}$

10. Palisadenzellengröße

$\mathrm{L}>\mathrm{H} \leq \mathrm{J}$

11. Interzellularräume

$\mathrm{L}>\mathrm{H} \geq \mathrm{J}$

12. Drusen- und Raphidenzellen

$\mathrm{L} \geq \mathrm{H}<\mathrm{J}$

Nach obigen Formeln ist die Blattstruktur des Bastards teils patroklin, teils matroklin, teils intermediär, und in gewissen Eigenschaften (Größe der Epidermiszellen, Zellenzahl der Drüsenhaare) iubertrifft der Bastard die Eltern, oder er bleibt hinter ihnen zurück (Größe der Palisadenzellen).

Fuir den Bau eines Organes, z. B. eines Blattes, ist also keineswegs eine Erbeinheit verantwortlich, sondern es kommen viele Faktoren in Frage, die unabhängig voneinander die Nachkommenschaft beeinflussen können. Die Größe der Epidermiszellen ist z. B. unabhängig von der der Palisadenzellen. Die Struktur des Bastardblattes ist das Gesamtresultat aus dem Zusammenwirken der einzelnen Gene, welche die Blattstruktur der Elternpflanzen bedingen. Es ist auch wohlbekannt, daß gewisse Merkmale der Eltern im Bastard verstärkt oder abgeschwächt erscheinen können.

Berlin-Dahlem, Kaiser Wilhelm Institut für Biologie.

\title{
Zusatz zur Arbeit „Über die musikalische Vererbung in der Descendenz von Robert Schumann" ${ }^{(1)}$ ).
}

Wir sind von Herrn Direktor Kreisig in Zwickau, Vorstand des Robert Schumann-Museum daselbst, freundlichst darauf aufmerksam gemacht worden, daß unsere Angabe (S. 100), Friedrich Wieck sei ein berühmter Flötenspieler gewesen, ihm zweifelhaft erscheint. Wir haben uns in der Tat überzeugt, dab die Quelle, auf der unsere Angabe berr.it, in diesem Punkt wohl nicht zuverlässig ist.

Bei dieser Gelegenheit bitten wir auch, S. 100, Anm. 3 hinzuzufügen: Bd. 1. - Die Angabe S. 101, Zeile 7 stützt sich auf Litzmann, l.c., Bd. 1, S. 5. Auch ist S. 101, Anm. 1 Bd. 3 statt Bd. 2 zu lesen. Endlich ist S. 106, Zeile 8 von unten väterlicherseits statt mütterlicherseits zu lesen.

Für unsere Schlußfolgerungen haben alle diese Abänderungen keine Bedeutung.

$$
\text { V. Haecker und Th. Ziehen. }
$$

1) Diese Zeitschr., Bd. 38. 1925. S. $97 \mathrm{ff}$. 